\title{
A Study of the Motivation and Etymology of Idioms
}

\author{
Fangfang Ding \\ Sichuan Agricultural University \\ Ya'an, China
}

\begin{abstract}
It is a significant task to compare the true etymology with the synchronically relevant motivational basis. And second, in the case of some idioms "etymological memory" may have a role to play in motivation. In these cases, a given idiom may exhibit restrictions on its use that can only be explained by addressing its history, i.e. these idioms cannot be used in contexts that are not compatible with their etymological origins.
\end{abstract}

Keywords—idioms; motivation; etymology

\section{INTRODUCTION}

The synchronic motivation of an idiom often does not coincide with the "true" etymology of that idiom, and sometimes the two can contradict each other. In such cases, the question arises whether it is the synchronic motivation or the etymology that is more important for the functioning of an idiom. This involves examining the external combinatorial restrictions of a given idiom. For any idiom this then becomes the question of whether any such restrictions can be explained by addressing the idiom's conceptual basis. If so, what are the motivational "bridges"? These could involve how most speakers intuitively construct such bridges (which often takes the form of folk etymology), or it could involve the true etymology of the idiom. Both possibilities are plausible, the latter on the assumption that an idiom's figurative past may be accessible in the present in the form of traces of an "etymological memory" so that even where speakers do not know the etymology, the idiom is not used in combinatorial surroundings that would violate a historically relevant type of context. The former possibility predicts that speakers use idioms according to the idiom's personal associations for the speaker, which need not have anything in common with the idiom's true etymology.

\section{TYPES OF MOTIVATION}

The prototypical idiom (the figurative idiom) can be interpreted on two different conceptual levels: on a primary level, i.e. on the level of its "literal" meaning which underlies its inner form, and on a second level, i.e. on the level of its figurative meaning. The latter is also called the lexicalized meaning which is the term we use in this paper. The so-called image component of an idiom takes the role of a semantic bridge between the two levels. What is meant by image component is neither the etymology nor the original image, but linguistically relevant traces of an image that are comprehensible for the majority of speakers. It is an additional conceptual link that mediates between the literal reading (fixed in the idiom's lexical structure) and the lexicalized meaning of an idiom, cf. similar ideas in Baranov and Dobrovol'skij (2008).

Motivation, which is the part of the inner form, involves the possibility of interpreting the underlying mental image in a way that makes sense of the meaning conventionally ascribed to it. Thus the conceptual structure of a motivated lexical unit includes not only the lexicalized figurative meaning and the relevant traces of the mental image (i.e. the inner form) but also the conceptual links between them. However, since it is difficult to investigate how individual speakers process a given lexical unit, only trends can be revealed by means of psycholinguistic experiments. There are various types of idiom motivation which we will now outline.

\section{A. Metaphoric Type of Motivation}

The motivational links that are relevant to metaphorically motivated idioms can most adequately be explained either on the superordinate level of the conceptual metaphor, i.e. on the level of the abstract metaphoric model (cf. Lakoff and Johnson 1980; Lakoff 1987) or on the basic level of categorization (following Rosch 1975, 1978) that is encoded in the lexical structure of an idiom. We call such "basic level cases" of motivation frame-based metaphors, cf. (1-2).

(1) to throw dust in someone's eyes

'to mislead or betray someone willfully'

(2) to be a red rag to the bull time'

'to be the cause for making someone very angry all the

Idiom (1) is motivated by the abstract conceptual metaphor deception is disturbance of seeing. Together with other figurative units (e.g. to pull the wool over someone's eyes 'to deceive, mislead someone', to muddy the waters 'to make things more confused by obscuring them', to cover up something, etc.), it forms a well-developed metaphoric model. For idiom (2), no such metaphoric model can be found. This idiom can be best described within the theoretical framework of the cognitive modeling of idiom semantics, developed by Baranov and Dobrovol'skij (cf. Baranov and Dobrovol'skij 1996, 2000, 2008). Idiom (2) is motivated by fragments of world knowledge about the frame bullfight. The meaningful elements that are significant for the lexicalized meaning are slots of this frame: torero, bull, instruments used by the torero, although not all of them are 
explicitly expressed in the lexical structure of the idiom. So, the motivation is based here on the conceptual correspondence between the source frame bullfight and the target frame cause to get angry, rather than on a kind of superordinate conceptual metaphor. From a purely linguistic point of view, it is not important under which conceptual metaphor idioms like (2) should be subsumed. We take it that this is a classification task rather than being of theoretical significance.

\section{B. Symbol-based Type of Motivation}

In idioms with symbol-based motivation, the relevant cultural knowledge mainly extends to one constituent (or more precisely, to the concept behind it) and not to the idiom as a whole (as is the case with the metaphoric type of motivation). The key constituents of "symbolic" idioms have clear semantic autonomy. The motivational link between the literal and figurative readings of these constituents is established by semiotic knowledge about the cultural symbol in question, especially its meaning in culturally relevant sign systems other than language, cf. (4).

(4) to keep the wolf from the door

'to ward off starvation or financial ruin; to maintain oneself at a minimal level'

The concept wolf with its symbolic functions 'hunger and greediness' and 'economic despair' plays the principal part in the semantic motivation of idiom (4). This agrees with the symbolic functions of wolf that are anchored in various cultural codes, ranging from fairy tales and folk tales of the dangerous, people-devouring wolf to folk beliefs about werewolves, and throughout Western history from antiquity to Christian exegesis up to present-day nursery rhymes, cartoons or film animations. Thus, in order to process idiom (4), other pieces of knowledge must be activated: the knowledge of the symbolization behind the constituent wolf. In most cases, the semantic procedures that underlie symbolbased motivation constitute a metonymical shift.

The difference between metaphoric motivation and symbol-based motivation is that the former involves the idea of some kind of similarity between the entity encoded in the inner form and the entity denoted by the idiom taken in its lexicalized meaning, whereas the latter exploits certain cultural conventions based on the ability of material objects to "stand for" some non-material entity.

\section{Intertextuality as Factor of Motivation}

Intertextuality is of the utmost importance given the cultural foundation of idioms. In this article, intertextuality is understood as the relationship of a conventional figurative unit (such as an idiom) with an already existing text as its cultural historical origin. There are a great number of figurative units whose image components can be traced back to an existing (mostly identifiable) textual source. Intertextuality is a result of the etymology of idioms (e.g. idioms taken from the Bible, Shakespeare, classical literature etc.), rather than a question of motivation. Nevertheless, in certain cases, intertextuality must be accounted for as a special type of motivation.

Several idioms can be regarded as motivated by intertextuality and by a certain frame or cultural symbol at the same time. However, there is a small group of idioms where we may assume that the intertextual motivation offers the only possibility for making sense of the idiom, i.e. for establishing the motivational link between the inner form and the lexicalized meaning of the idiom. Let us first consider such an idiom, (5).

\section{(5) a/the Trojan Horse}

'a deception, a concealed danger; an enemy concealed within someoneor something that attacks the group or organization he/she/it belongs to'

Idiom (5) is currently very well-known in computing, as a program with a concealed function that damages other programs on the computer to which it is downloaded. The idiom is either opaque to speakers or motivated by intertextuality. A semantic motivation can be excluded. It is motivated by knowledge that there is a story behind it, even if this story may not be mentally present with all its details to every speaker. Homer reports in his Odyssey (and Virgil in his Aeneid) that, after Hector's death, Ulysses had a huge wooden horse made and declared that it was an offering to the gods to secure a safe voyage back to Greece. The Trojans dragged the horse within their city, but it was filled with Greek soldiers, including Menelaus, who stole out of the horse at night, slew the guards, opened the city gates and set fire to the city. This phrase, in the sense of an imminent and great danger, became proverbial as early as in Roman antiquity (Pohlke 2008: 219).

Other idioms of intertextual origin can also be motivated for speakers by different knowledge structures (e.g. metaphors or symbols), cf. (6-7).

(6) to run/approach with seven-league boots

'to run/approach very quickly'

(7) a snake in the grass

'a secretly untrustworthy or treacherous person; a great danger'

Idiom (6) seems to be motivated intertextually for people who are familiar with the tales of the seven-league boots, which magically enable a giant to take great strides and approach very fast. They are a motif in folktales, cf. the fairy tale "The Seven-leagued Boots" and various literary treatments of the theme (for German, e.g. by Wilhelm Hauff and Adalbert von Chamisso). The lexicalized meaning then would be 'to run/approach very quickly, as if someone was the giant of the tale whose boots carry him/her seven leagues at a step'. For people who are unfamiliar with the textual source, the idiom may be motivated in part by their symbolic knowledge of the number seven which has, among others, the symbolic meaning 'many, much' ('intensification'). The ability to make strides of seven leagues clearly results in great speed. 
Similarly, idiom (7) has its origin in classical literature (it is a quotation from Virgil's "Eclogues": latet anguis in herba 'there is a snake hiding in the grass', $37 \mathrm{BC}$ ). Its motivation for the average speakers, however, is likely based on knowledge about snakes (they actually hide in tall grass, and their bite is dangerous), on the one hand, and symbolic knowledge (snake is a strong cultural symbol signifying 'danger', 'evil', 'malice'), on the other. Thus, idioms that have roots in works of literature, fables, fairy tales etc. may be motivated by their "true" etymological origin for speakers who are familiar with the textual source, while other speakers can often activate other knowledge structures to make sense of the idiom. In what follows we will look at the issue of idiom etymology in more detail.

\section{ASPECTS OF ETYMOLOGY}

\section{A. Historical and Etymological Research on Idioms}

The aims of historical comparative approaches to phraseology are many, ranging from uncovering the etymological origin or the initial form of single phrasemes to reconstructing former stages in the development of a phraseological system or entire domains that were previously culturally significant. This branch of research has to rely on cooperation with culturally-oriented academic disciplines other than linguistics (e.g. folklore, mythology research, ecclesiastical history) and to incorporate dialectal and historical language varieties as well as comprehensive extralinguistic material.

First, it is crucial to discriminate between historical research and etymological analysis. As for historical research, there is such a tradition in Slavic languages. Since the 1960s, several studies have analyzed dialectal and ethnographic material in order to reconstruct the phraseology of a ProtoSlavic variety (Tolstoj 1973) and aspects of early religious and mythological concepts of folk culture. Using variants or (quasi)-synonyms of a given phraseme in many dialects and related languages as a starting point, Mokienko (1989) develops structural semantic models. This approach finds expression in further diachronic studies, above all in the historical-etymological dictionary of phrasemes (Bierich et al. 2005).

In contrast to that, other significant etymological studies start from the particular phrasemes themselves in order to advance to their real origins or sources. Recently, Wanzeck (2003) has given a coherent description of the etymology of idioms containing color words in historical and current use. Starting from the lexicalized meaning of the phrasemes, the study centers on the question of how the color adjectives took on their phraseologically bound meanings. Exhausting the written sources from the very beginning and considering their cultural and historical contexts, the author succeeds in clarifying the true etymology of many phrasemes that became obscure in the course of history. For example, she was able to illuminate how the German idiom (8), completely opaque until then, came into being.

\section{(8) German einen blauen Montag machen}

$$
\text { "to make a blue Monday" }
$$

$$
\text { 'to skip work on Monday' }
$$

Since medieval times there was a "blue mass" (German blaue Messe) that was said for the deceased of a craftsmen's guild on a particular Monday. It was also named blauer Montag, after the priest's blue vestment, since with regard to ecclesiastical history, blue was the color of fasting and mourning. Through various social historical circumstances, the meaning shifted from 'requiem mass on a Monday' to 'Monday off' (Wanzeck 2003: 156-211).

This example shows that knowledge of its etymology mostly has no effect on the way speakers deal with an idiom. Unlike with idioms that are obviously transparent (e.g. because of a well-known underlying source frame), play on words with the historical meaning of blue (the color of the priest's vestment, ecclesiastical color of mourning) would not be possible.

\section{B. Folk Etymology}

Motivation exists only in those cases where the image component is alive. This can be the (historically) true etymology, but it can also be a reinterpretation of the original concept, a "modernized" folk etymology, brought into line with the extra-linguistic facts that are encoded in the inner form. This can be illustrated by the idiom to give someone the green light 'to give someone permission to do something that they were planning'. It originates historically in the signals used in early railroad systems and not in urban traffic lights, although, from a contemporary view, the image component seems to be grounded in the regulation of road traffic, when the light switches to green signaling road users to proceed. Compare also idiom (9).

\section{(9) to hit the nail on the head}

'to describe something in exactly the right way, to find exactly the right answer to a problem in one or two words'

The idiom is clearly motivated (for the average speaker) by fragments of world knowledge about the function of nails (as a tool). The allusion is to an accurate blow with a hammer on the head of a nail, which requires some skill. There is a homomorphic relation between the literal and figurative meaning: the head of the nail is the central point of a matter, while to hit correlates with 'to grasp, capture something concisely and appropriately'. Thus, the idiom is semantically decomposable (in the sense of Dobrovol'skij 1982; Nunberg et al. 1994 or Langlotz 2006). When historical correspondences are taken into account, however, the correlation is different, resulting in a complete shift of the image. The true etymology is based on medieval knighthood and archery, where a target was fixed to the wall with a nail, exactly in its center. The best bowman was able to hit precisely on the nail. This true etymology can be proven by historical evidence. We find a clear reference to the bowman in a German equivalent in one of Martin Luther's texts (1541): das ein guter schütze den pflock odder nagel treffe ["that a good archer may hit the tack or nail"] (Cornette 1997: 88). Presumably, the earliest English pieces of evidence were also used with reference to the archery frame (cf. Thou hittest the nayle on the head, ca. 1520, 
Apperson 1969: 435). It is impossible to say at what time the shift of the mental image (in the direction of the hand tool) took place.

These examples show that shifts from true to folk etymology do not have clear consequences for the usage of an idiom. The crucial factor is whether speakers perceive the idiom as motivated or opaque.

\section{Cultural History}

Phraseology is a linguistic domain that, due to its interrelation with culture, can be better explored and understood in a cultural and historical context than merely in a synchronic perspective. Every idiom has its history or "biography" and can be categorized according to its cultureboundness (cf. Sabban 2008). In the course of history, an idiom may undergo various influences. The impact of cultural and historical features is evident in the evolution of an idiom. It is unpredictable how its outward structure and figurative meanings will develop. In addition to that, the interpretation of the underlying mental image can be subject to historical transformations, as example (9) has shown. This must especially be kept in mind when looking at the etymology. Let us illustrate this point with idiom (10).

\section{(10) to look for a needle in a haystack}

'to try to find something very small that is lost among many other things; to struggle with searching for something without any prospect of success'

Taylor (1962: 190) assigns the idiom to the domain "household", based on the constituent needle (together with the idiom to be on pins and needles), although the domain "country life", which is also mentioned by Taylor, would probably be more adequate (because of the constituent haystack ). However, there is an entirely different way in which the idiom can be assigned to a certain cultural domain. There are many folktales involving futile searches for objects. Most probably, the idiom refers to one of them, the jester's tale of a fool who is hunting for a needle in a haystack. The Grimms' fairy tale No. 32, Clever Hans, tells us about a fool who puts a needle into a hay cart where the needle later must be found (Aarne/Thompson 1961 No. 1685). If there is a synchronically relevant connection to this once well-known narrative motif, the cultural domain in question must be defined in different terms. It is no longer an aspect of "material culture" but a fragment of the knowledge domain of "intertextuality". At the same time, idiom (10) is connected to a group of narrations which have been wellknown since ancient or medieval times and live on as short forms in modern idioms.

\section{Intertextuality from the Etymological Perspective}

There are thousands of idioms that go back to an identifiable textual source (originally either direct quotations from an author's work or allusions to an entire text passage). A large set of idioms is traceable to classical antiquity, to the Bible or narrative traditions. Even film productions are a modern textual source. Some of these idioms belong to the motivation type of "intertextuality".
Out of the different strands of intertextual tradition, only one has been studied in more detail so far: idioms of biblical origin. Many idioms date from translations of the Bible. Larger, however, is the proportion of idioms in contemporary languages that were already very popular with classical authors (including many inconspicuous idioms with nothing to suggest their classical origin). This strand of tradition is not as well researched as the phenomenon of biblical idioms. The works of Erasmus of Rotterdam alone contain hundreds of expressions that live on to this day in modern languages.

Further sources that should be mentioned when discussing the intertextual origins of idioms include idioms going back to fables of the Aesopic type like to bell the cat 'to undertake a dangerous mission at great risk to oneself for the sake of others', the lion's share 'the biggest part of something that is taken or done by one person instead of being shared fairly with other people'), to fairy tales (cf. idiom (6) or, for example, to be a bird in a gilded cage 'to live in affluence, prosperity but lacking freedom', to animal tales (as poor as a church mouse 'very poor, possessing nothing', to fight like cat and dog 'to frequently have violent arguments with each other, to keep quarrelling with each other all the time') and all the other kinds of folk tales, jests and comical tales that once were well-known but fell into oblivion in the course of history and survive in idioms of the present day, as is supposedly the case with idiom (11) above.

These examples clearly show that no generalizations can be made in this field because every idiom has undergone its own development in the course of its history. What these examples make evident is that the task of describing true etymology must be strictly separated from the task of revealing productive motivating links that influence the idiom's functioning in discourse.

\section{CONCLUSION}

As a rule, the image component is involved in the cognitive processing of the particular idiom. This means that relevant elements of the inner form have to be included in the structure of the semantic explication of idioms. Since the majority of idioms are semantically motivated, we need to distinguish between two principal types of semantic motivation: the metaphoric motivation type and the symbolbased motivation type. Both types can additionally be affected by a third, not purely semantic type of motivation, namely intertextuality.

\section{REFERENCES}

[1] Aarne, Antti \& Stith Thompson. 1961. The types of the folktale: A classification and bibliography. Helsinki: Suomalainen Tiedeakatemia.

[2] Apperson, George Latimer. 1969 [1929]. English proverbs and proverbial phrases: A historical dictionary. London \& Toronto: Dent.

[3] Baranov, Anatolj \& Dmitrij Dobrovol'skij. 1996. Cognitive modeling of actual meaning in the field of phraseology. Journal of Pragmatics 25. 409-429.

[4] Baranov, Anatolj \& Dmitrij Dobrovol'skij. 2000. Tipologija formal'nyx operacij pri poro`zdenii aktual'nogo zna`cenija idiomy. 
[Typology of formal operations at generation of idioms' actual meaning] Linguistische Arbeitsberichte 7. 7-20.

[5] Baranov, Anatolj \& Dmitrij Dobrovol'skij. 2008. Aspekty teorii frazeologii. [Aspects of a theory of phraseology] Moscow: Znak.

[6] Cornette, James. 1997. Proverbs and proverbial expressions in the German works of Martin Luther. Bern et al.: Peter Lang.

[7] Dobrovol'skij, Dmitrij O. 1982. Zum Problem der phraseologisch gebundenen Bedeu-tung. Beiträge zur Erforschung der deutschen Sprache 2. 52-67.

[8] Lakoff, George \& Mark Johnson. 1980. Metaphors we live by. Chicago \& London: Chicago University Press.

[9] Lakoff, George. 1987. Women, fire, and dangerous things: What categories reveal about the mind. Chicago \& London: Chicago University Press.

[10] Langlotz, Andreas. 2006. Idiomatic creativity: A cognitive-linguistic model of idiom-representation and idiom-variation in English. Amsterdam: Benjamins.

[11] Mokienko Valerij M. 1989. Slavjanskaja frazeologija [Slavic phraseology]. Moscow: Vys`saja `skola.

[12] Nunberg, Geoffrey, Ivan A. Sag \& Tomas Wasow. 1994. Idioms. Language70. 491-538.

[13] Pohlke, Reinhard. 2008. Das wissen nur die Götter: Deutsche Redensarten aus dem Griechischen. Düsseldorf: Patmos.

[14] Rosch, Eleanor. 1975. Cognitive representations of semantic categories. Journal of Experimental Psychology: General 104. 192233.

[15] Rosch, Eleanor. 1978. Principles of categorization. In Eleanor Rosch \& Barbara B. Lloyd(eds.), Cognition and categorization, 27-48. Hillsdale NJ: Erlbaum.

[16] Sabban, Annette. 2008. Critical observations on the cultureboundness of phraseology. In Sylviane Granger \& Fanny Meunier (eds.), Phraseology: An interdisciplinary perspective, 229-241. Amsterdam \& Philadelphia: Benjamins.

[17] Taylor, Archer. 1962. The proverb and an index to the proverb. Hartbo: Folklore Associates.

[18] Tolstoj, Nikita I. 1973. O rekonstrukcii praslavjanskoj frazeologii. [On reconstruction of the Proto-Slavic phraseology]. In Slavjanskoe jazykoznanie. VIII Me`zdunarodnyj s'ezd slavistov. Doklady sovetskoi delegacii, 272-294. Moskva: Nauka.

[19] Wanzeck, Christiane. 2003. Zur Etymologie lexikalisierter Farbverbindungen. Unter-suchungen anhand der Farben Rot, Gelb, Grün und Blau. Amsterdam \& New York: Rodopi. 